\title{
Seismic vulnerability maps of Timisoara historical center based on fragility curves
}

\author{
S. Taffarel, C. Marson, C. Valotto, M. Roverato, M. Munari, F. da Porto \& C. Modena \\ University of Padova, Department of Civil, Environmental and Architectural Engineering, 35131 Padova, \\ Italy \\ M. Mosoarca \\ Politehnica University of Timişoara, Faculty of Architecture and Urban Planning, 300223 Timişoara, \\ Romania
}

\begin{abstract}
The seismic vulnerability assessment on a territorial scale requires the application of simplified procedures. Data collection is usually carried out by adopting external inspections; for this reason the knowledge gained for the considered buildings is usually not complete and lack of information has to be managed. The definition of a methodology which takes into account these aspects is one of the aims of this paper. Another goal is the extension of the obtained results to buildings not directly surveyed on site, whose characteristics are similar to those of the analyzed buildings.

The case study of Timisoara (Romania) is presented. A rapid survey of the historical center is performed and recurring typologies are identified. Analyses of the most significant local mechanisms of collapse are implemented, taking into account possible parameters variation. Fragility curves for each typology are then obtained allowing the definition of vulnerability maps for the whole historical center.
\end{abstract}

\section{INTRODUCTION}

A key element in the development of prevention strategies and in the forecasting damage caused by seismic events in historical buildings is the analysis of their structural behavior (da Porto et al., 2012). Vulnerability assessment is a fundamental step in order to reduce the seismic risk of existing constructions (Cialone et al. 2013, Modena 2014, Modena et al. 2013).

This paper refers to the seismic vulnerability assessment of the historic center of Timisoara, in the region of Banat (Romania).

By the implementation of reliable analyses, the adopted methodology is based on a rapid survey that allows the definition of the seismic damageability of ordinary masonry aggregate buildings of the whole historical center. The obtained seismic vulnerability maps represent useful tools for municipal administrations in order to define priorities of intervention. Firstly, a preliminary knowledge of the urban development of the historic center is required, studying recurrent constructive techniques, technologies, urban and architectural features. Data gathered during the survey activities are included in specific forms filled out on-site and calibrated on the analyzed case study, thanks to the information obtained during the preliminary knowledge phase (Taffarel et al., 2014). After the on-site activity, collected data are analyzed by applying statistical and typological evaluation in order to identify the most common buildings features and to define typologies representing the analyzed structural units (SU). For the Timisoara case study, thirty-three typologies are recognized, characterized by different stories number, vertical and horizontal structures and roof types.

The response of single typologies under seismic actions is individually analyzed by using capacity curves resulting from the implementation of local mechanisms of collapse (simple overturning and vertical bending). Fragility curves describing the conditional probability of a structure to match or exceed a certain seismic damage state considering various levels of peak ground acceleration are then obtained.

The aim of this study is to define vulnerability maps for Timisoara historical center and extend the proposed methodology to other city districts and to other historical city centers which are characterized by the same or similar architectural and typological features. 


\section{DESCRIPTION OF TIMISOARA CASE STUDY}

\subsection{A general urbanistic overview of the analyzed area}

Timisoara is the main town of Timis County and is considered the informal capital city of the historical region of Banat, in western Romania.

The first documentation about the city organization dates back to the XII century, when Timisoara belonged to the Kingdom of Hungary. In 1718, under the Habsburg domination, Timisoara became the capital city of Banat and Prince Eugene of Savoy issued a "Building Regulation" for the town, ordering the demolition of all existing buildings and their new organization within a rectangular street network; compulsorily buildings had to be reconstructed using bricks.

The majority of analyzed blocks are located in the historic city center, the so called district of Cetate. Another analyzed area is Iosefin district, located at south-west of the city. The XVIII century urban plan still rules current city configuration. Buildings dated in the first half of the century occupy the inner part of the center, while constructions belonging to the period between the half of the XVIII century and the half of the XIX century occupy suburban spaces located inside old fortifications.

During the 1848-1849 Revolution, many buildings where partially destroyed by bombing, so between the end of the XIX century and the beginning of the XX century many constructions were rebuilt, often conserving not destroyed ground floors and rebuilding upper floors. The district of Iosefin developed at the end of the XVIII century as an answer to the lack of space in the city center. Analyzed blocks are dated to the second half of the XIX century (Figure 1).

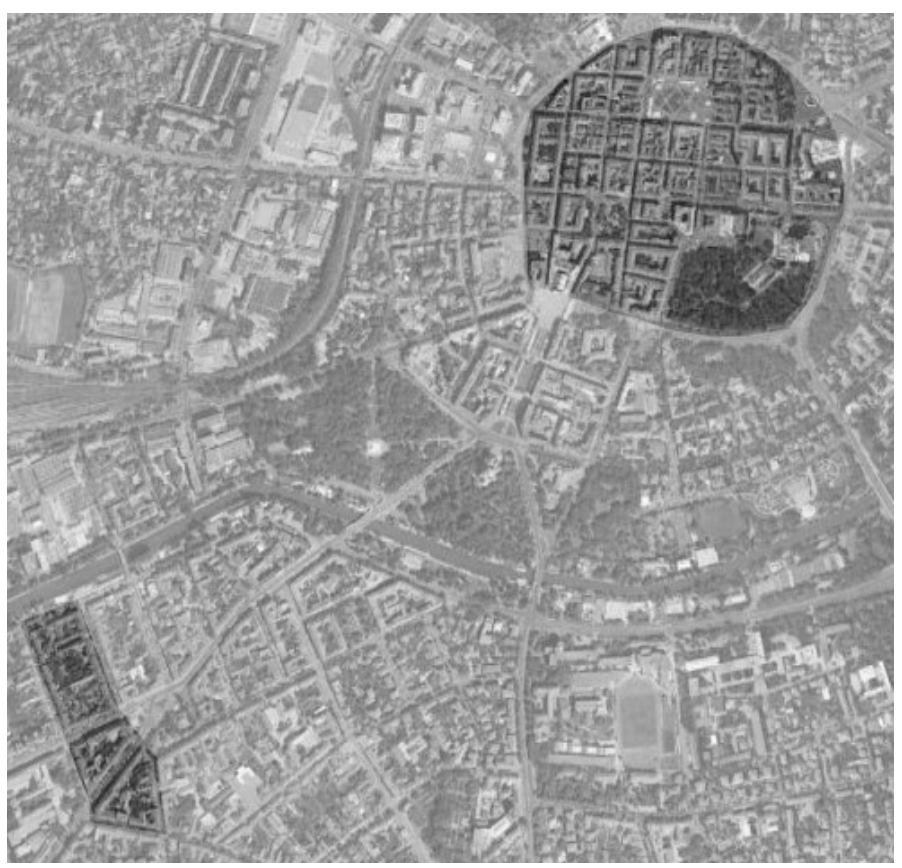

Figure 1. Identification of analyzed areas: Cetate district (on the right) and Iosefin district (on the left).

\subsection{Seismicity}

The western part of Romania is located in the contact area between the Pannonian Depression and the Carpathian Orogen. Two distinct seismic areas can be defined on the basis of seismicity distribution: Banat zone at south and Crisana-Maramures zone at north (INFP 2013). Considering the energy and the number of seismic events, Banat region is considered as the second most hazardous seismic zone in Romania and is subjected to shallow earthquakes. In this area, earthquakes are generated at a depth between 5 and $15 \mathrm{~km}$, with a reduced surface of the epicenter area where the effects are greatest (Mosoarca et al., 2014). Earthquakes are characterized by short periods of vibration which affect massive masonry structures, pulse actions with a powerful first cycle and a rapid attenuation, horizontal and vertical components of approximately the same size. The distribution of epicenters of the region recorded earthquakes shows that they can be clustered in three major areas defined by important seismic events having magnitude $\mathrm{M} \geq 5.0$ : an area is near Timisoara in correspondence of Sag (M=5.4 on 27 May 1959) and Timisoara-Sacalaz (on 5 June 1443 and on 19 November 1879), two areas are located at a critical distance from Timisoara, causing minimal effects on the buildings, another area is in Volteg-Barloc $(\mathrm{M}=5.6$ on 12 July 1991 and $\mathrm{M}=5.5$ on 2 December 1991) and another one is between Lovrin and Vinga $(\mathrm{M}=5.3$ on 30 August 1941 and $\mathrm{M}=5.2$ on 8 July 1938) (Oros, 2012).

Timis County includes zones having a mean earthquakes recurrence interval of 50 and 100 years, which can be evaluated in terms of peak ground acceleration (PGA) between $\mathrm{ag}=0.10 \mathrm{~g}$ and $\mathrm{ag}=0.25 \mathrm{~g}$. Considering the town of Timisoara, the national code defines a reference value for the PGA equal to $0.2 \mathrm{~g}$. However, a lot of existing buildings were not designed for seismic actions, or were designed for smaller values of ground acceleration (Mosoarca et al., 2014) highlighting the need to assess their seismic behavior.

Banat region can reach a maximum magnitude of $M=6-6.5$, corresponding to an intensity of $\mathrm{I}_{0} \geq \mathrm{IX}$ MSK.

Considering historical events occurred in the region, the most important ones are: October 1879 and April 1880 in Moldova Noua area; May 27th 1959 near Timisoara city $(\mathrm{M}=5.6)$, followed by two shocks occurred in 1960; July 12th 1991 in Banloc $(M=5.6)$; December 2nd 1991 in Voiteg $(\mathrm{M}=5.6)$, followed by a huge number of aftershocks (INFP 2013). 


\subsection{Blocks identification: typological, architectural and urban features}

Cetate blocks are regulated by a grid of perpendicular streets. Usually, blocks have a rectangular shape, whose length may range from 50 up to $100 \mathrm{~m}$. If they are located near the fortified walls of the city center, they often have triangular or polygonal shapes . Blocks are constituted by aggregate buildings following the rigid grid of streets, and are characterized by the presence of internal courtyards (Figure 2). They can also be characterized by a single building developed around the internal courtyard. Masonry buildings in the city center are usually used for residential purposes and are characterized by 2 or 4 stories (only few cases of 1 or 5 stories building are identified). Almost the totality of buildings has basements or underground floors; practicable attics are often the result of recent intervention. The majority of buildings are regular in elevation and in plan shape. Elevation irregularities are often caused by later raised parts.

Vertical structures are composed by brick masonry and their thickness usually decreases from the underground to the upper floors $(90$ or $105 \mathrm{~cm}$ on the basement, reduced to 45 or $60 \mathrm{~cm}$ at the upper floors).

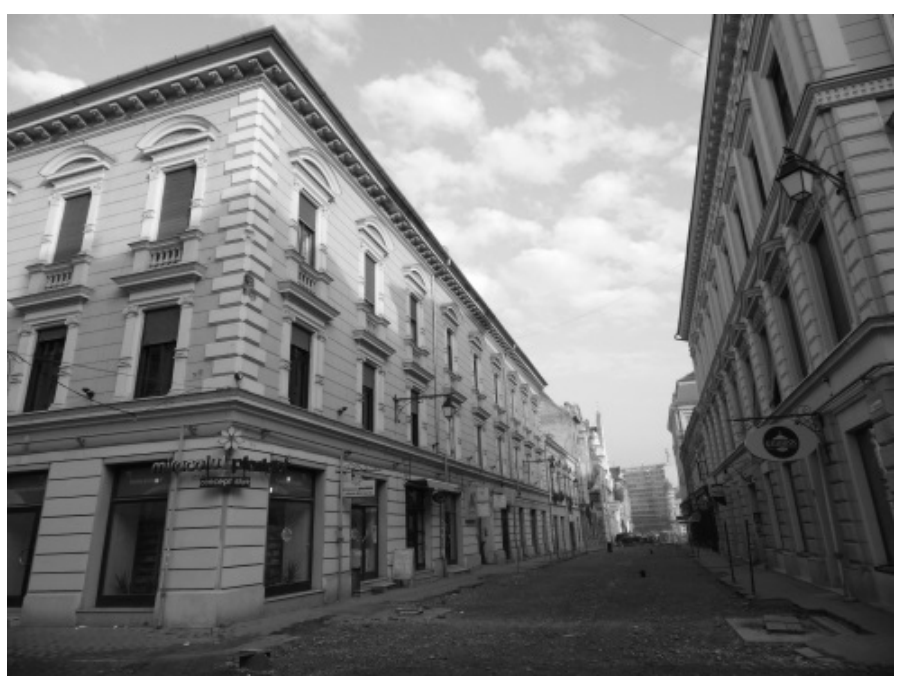

Figure 2. Aggregate buildings located in Cetate district.

Basements and underground horizontal structures are usually characterized by brick vaults and only in few cases by iron beams and little brick vaults. On the ground floor brick vaults were usually built in during the XVIII century; iron beams and little brick vaults were used during the second part of the XIX century; iron beams and low brick vaults were adopted at the beginning of the XX century. Upper floors horizontal structures and roofs were usually made of wood; in the latest years recurrent interventions on historical buildings were the substitution of timber horizontal structures with concrete slabs and the reconstruction of roofs by using wood and con- crete mixed structures. Facades are usually characterized by a huge number of openings that usually exceeds the $30 \%$ of the total surface, reducing bearing walls extension.

Iosefin blocks follow a grid urban pattern too, but not as rigid as the Cetate one. Blocks can reach a dimension up to $250 \mathrm{~m}$ per side, each one including 20 or more SU. Buildings are 1, 2 or 3 stories high. The most common horizontal diaphragms are timber floors or iron beams with very low rise brick vaults on the ground floor, brick vaults or iron beams with little brick vaults at the basement and timber structures at the upper floors. Roofs are usually made of wood but, as in Cetate district, many substitution intervention of wooden structures with concrete ones have been made in the latest years.

The majority of buildings presents added bodies and, as in the city center, almost all the constructions have a covered walkway to access the internal courtyard.

\section{FROM THE ON SITE SURVEY TO THE TYPOLOGICAL CLASSIFICATION: MAIN STEPS}

\subsection{On site survey and definition of typologies}

Data collected during the on-site activity are included in specific forms, calibrated to the specific case study features. The form includes SU collected information related to:

- general information about buildings location (street, street number, other information), age and previous interventions;

- geometrical data such as the number of stories, plan area, heights, percentage of holes in façade;

- typological data about vertical structures, horizontal structures and roofs;

- buildings regularity and vulnerability factors;

- level and extension of damage.

Data about 243 on site surveyed SU are then statistically analyzed in order to identify the main representative features of aggregate buildings, allowing the definition of recurring typologies within the area. Each real SU is then linked to the suitable simplified typology (Figure 3). In particular, 33 typologies were defined, focusing on the following main buildings characteristics:

- vertical structures: the majority of buildings are made of bricks;

- horizontal structures: three categories are defined, considering suitable ranges of permanent loads;

- number of out-of-ground floors. 


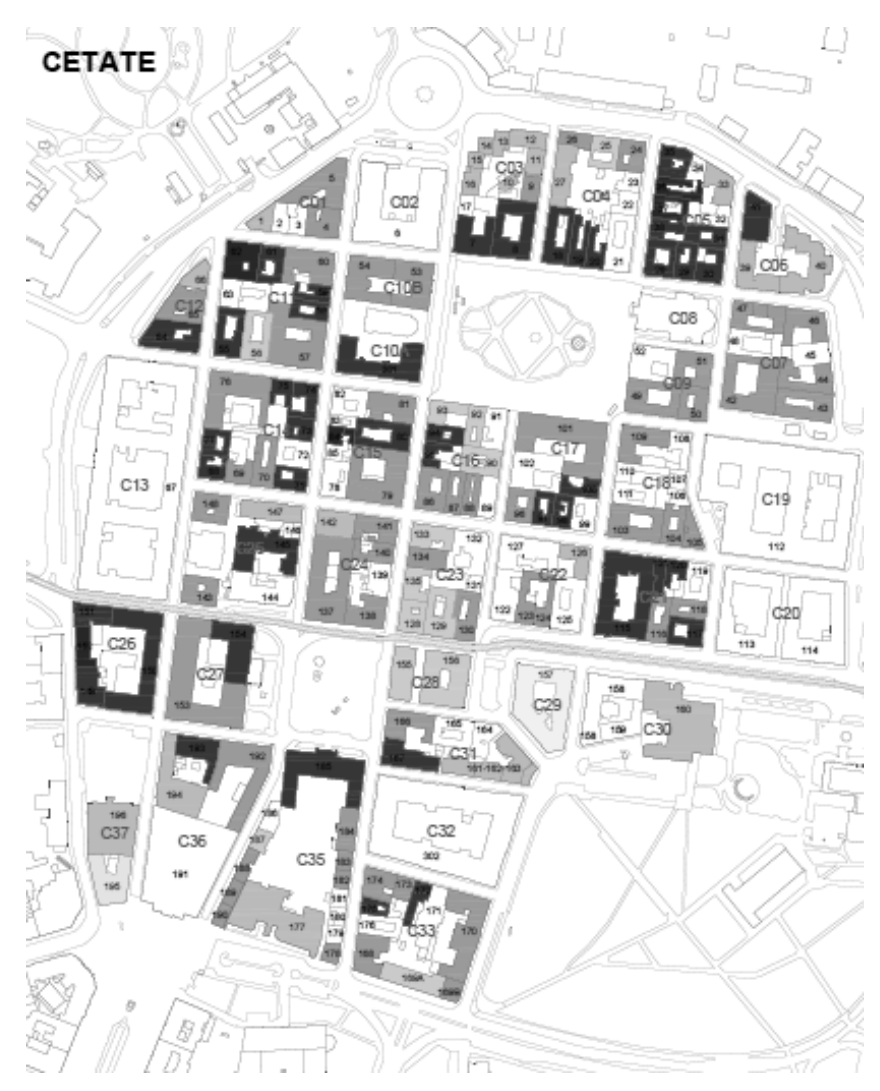

Figure 3. Typologies identification for Cetate district.

\subsection{The implementation of a parametric approach}

The application of methodologies for assessing buildings vulnerability considering survey uncertainties allows to significantly extend the analysis, including buildings where a lack of information about one or more features (geometric or typological ones) is identified. When a survey is based on buildings outside inspection, there are many difficulties in the definition of structural elements, (i.e. interstorey height, wall thickness, typology of horizontal diaphragms and quality of connection between bearing elements). In order to take into consideration their variability, some numerical ranges for both geometrical characteristics and loads are defined from data obtained through on site surveys, literature or expert judgments.

The parameters variation is performed for all the identified typologies and involves:

- wall thickness: a double analysis is performed considering both a constant wall thickness along the entire building height and a $15 \mathrm{~cm}$ wall thickness reduction until a realistic minimum thickness of $30 \mathrm{~cm}$;

- interstorey height;

- horizontal diaphragms: the variations are performed both in terms of structural typologies and geometrical characteristics.

\section{IMPLEMENTED PROCEDURE TO ASSESS THE SEISMIC VULNERBILITY}

\subsection{Local mechanisms of collapse}

During seismic events, clustered buildings often developed local failure mechanisms (NTC 2008, Circular n.617 2009). In Timisoara, out-of-plane local mechanisms were usually recorded in the upper part of the buildings, while in the lower part in-plane mechanisms were observed. The application of local technologies, such as the use of steel tie bars inside walls, adopted in the Banat region (Narita, 2015), contribute to improve buildings seismic behavior. Earthquakes often cause the collapse of parts of masonry aggregate buildings, usually related to the loss of equilibrium of walls portions. Out-of-plane local mechanisms analyses are performed using the limit equilibrium analysis, by adopting a kinematic approach. The identification of most probable collapse mechanisms, the definition of ground acceleration levels that activate the mechanism and the control of the evolution of the mechanism until the collapse is reached are the basis of this approach (NTC, 2008, Circular n.617, 2009). The most probable local mechanisms analyzed in this study are simple overturning and vertical bending (Figure 4).

Typological assumptions and parameters variation ranges play a fundamental role in this context, considering that buildings typological and structural characteristics influence the seismic behavior of constructions.
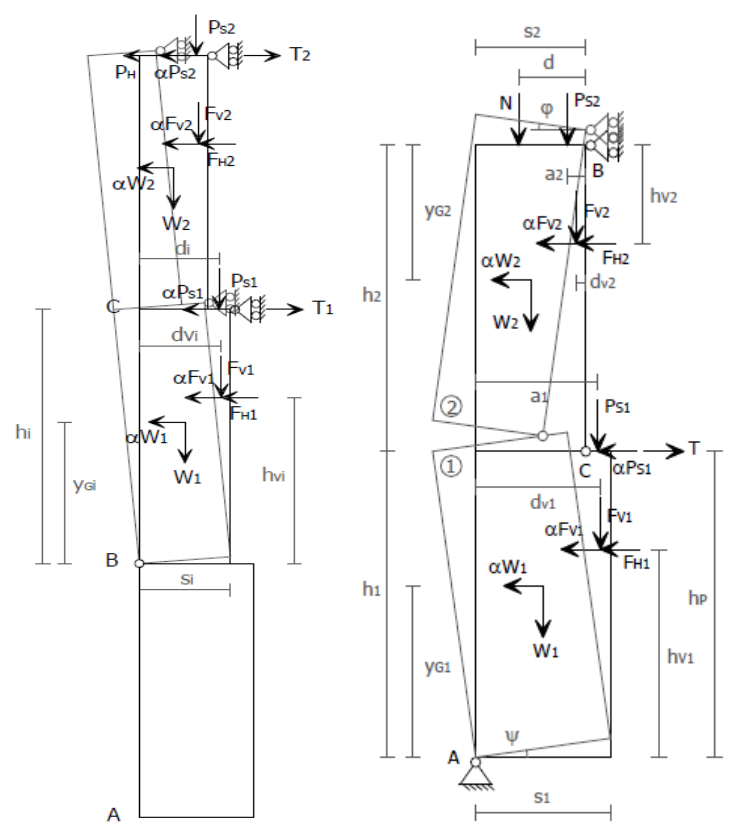

Figure 4. Representation of the main forces involved in the analysis of the simple overturning (left) and vertical bending (right) local mechanism of collapse (source:http://www.reluis.it/doc/emergenza_terremoto_abruzzo /Schede_Meccanismi.pdf) 
In this regard, parameters influence in terms of variation of the horizontal loads multiplier $\alpha_{0}$, that define the horizontal static equivalent forces and identify the beginning of the overturning or bending mechanism, was considered. For example, by means of sensitivity analyses it was observed that the parameter "floors area" (that measures the area of the horizontal diaphragm that bear on the walls involved in the mechanism) does not significantly alter results, so it has been excluded from the variated parameters and considered as a fixed one, defined evaluating the average area of buildings rooms. On the contrary, data related to horizontal diaphragms typologies usually heavily affect the analyses results. In general, both for overturning and vertical bending, the increase of buildings walls thickness or number of floors causes an improvement in results (increase of $\alpha_{0}$ multiplier).

As an example, analyses about walls overturning show that the value of $\alpha_{0}$ :

- is usually higher if the hinge is located at upper levels and lower if it is located at the ground floor. The same behavior is not experienced if walls are considered freestanding or if vaults are absent at the ground floor (as mentioned before, vaults are the main horizontal structure in Timisoara buildings ground floors);

- can be negative if high values of vaults thrust are considered, especially in the case of cross vaults located on buildings ground floors. In this case, the overturning moment is higher than the stabilizing one. This condition should bring to the collapse of the analyzed wall in static conditions, but, considering that no instability was noticed in the actual state, it is sensible to think that there are undetectable, but effective reinforcing elements. Moreover, different hypotheses about vaults geometric configurations should be considered.

Considering vertical bending involving one floor, the analysis is carried out defining the possible formation of a cylindrical hinge at vaults spring (usually located on ground floors) as a consequence of horizontal vaults thrusts. In case of vertical bending mechanism, wall thickness is the most influential geometrical feature, followed by ground floor interstorey height.

After the application of the abovementioned parameter variations to each local mechanisms of collapse, the procedure therefore allows the definition of a set of capacity curves. They correlate the displacement of a control point of the structure with the horizontal acceleration that the system is able to withstand and are fundamental in order to obtain fragility curves referred to specific levels of damage. Capacity curves are then compared in order to assess their trend and analyze a proper procedure to group them, also considering previously defined typologies, number of out of ground floors and local mechanisms of collapse type.

\subsection{Implementation of fragility curves for the local mechanisms of collapse}

Considering buildings undetectable characteristics, it is necessary to associate them a measure of uncertainty.

In order to evaluate the level of seismic damage which could affect buildings during an earthquake, the capacity of structures can be compared with associated levels of seismic demand analyzing the relationships between displacements required by seismic demand and structure actual performance. The seismic demand is influenced by intensity and site features.

Fragility curves are obtained correlating capacity curves and seismic demand. These curves express the conditional probability of an element to match or exceed a certain damage state (or performance level) for various levels of ground shaking IM, typically the peak ground acceleration (PGA) or the spectral acceleration (Sa).

Due to this, the performance of the structure is not identified by a single value, but from a range of points (intersection between the capacity curve and the demand ones).

Levels of damage definition proposed in scientific literature could take into consideration different parameters, particularly considering each structural element and sub-elements (local indexes) or the entire structure (global indexes). The most common parameters used for the evaluation of structural damage are ductility (expressed by rotation, curvature or displacement) and plastic energy dissipation. Considering the non-linear kinematic analysis, the i-th damage level is calculated starting from the ultimate spectral displacement of the one degree of freedom equivalent oscillator. Criteria proposed to define damage levels are summarized in Table 1 (Lagomarsino et al. 2014)

The variation of earthquake intensity is considered by adopting different PGA values, with a range from $0.0 \mathrm{~g}$ up to $0.4 \mathrm{~g}$ with steps of $0.05 \mathrm{~g}$. The value proposed by Romanian code for the town of Timisoara is the medium one $(0.2 \mathrm{~g})$. Eight elastic response spectra are determined (Figure 5), considering the type of soil (ground type C) defined by Eurocode (EN 1998-1:2010).

Table 1. Level of damage definition.

\begin{tabular}{|l|l|}
\hline $\mathrm{DLi}$ & Single block or Single Macro-element \\
\hline \multirow{3}{*}{$\begin{array}{l}\text { Minor } \\
1\end{array}$} & $\begin{array}{l}\text { In terms of percentage of the horizontal mul- } \\
\text { tiplier associated to } \mathrm{d}_{\mathrm{DL} 2}\end{array}$ \\
& $\mathrm{~d}_{\mathrm{DL} 1}$ corresponds to the point in which the \\
multiplier is $\alpha_{\mathrm{DL} 1}=0.7 \alpha_{\mathrm{DL} 2}$
\end{tabular}




\begin{tabular}{|l|l|}
\hline 2 & $\begin{array}{l}\mathrm{d}_{\text {peak }} \\
\mathrm{d}_{\text {DL2 }}=\min \left(\mathrm{d}_{\mathrm{y}} ; \mathrm{d}_{\text {peak }}\right)\end{array}$ \\
\hline $\begin{array}{l}\text { Extensive } \\
3\end{array}$ & $\begin{array}{l}\text { In terms of percentage of the ultimate dis- } \\
\text { placement capacity } \mathrm{d}_{0} \\
\mathrm{~d}_{\text {DL3 }}=0.25 \mathrm{~d}_{0} \geq \mathrm{d}_{\text {DL2 }}\end{array}$ \\
\hline $\begin{array}{l}\text { Complete } \\
4\end{array}$ & $\begin{array}{l}\text { In terms of percentage of the ultimate dis- } \\
\text { placement capacity } \mathrm{d}_{0} \\
\mathrm{~d}_{\text {DL4 }}=0.4 \mathrm{~d}_{0} \geq \mathrm{d}_{\text {DL2 }}\end{array}$ \\
\hline
\end{tabular}

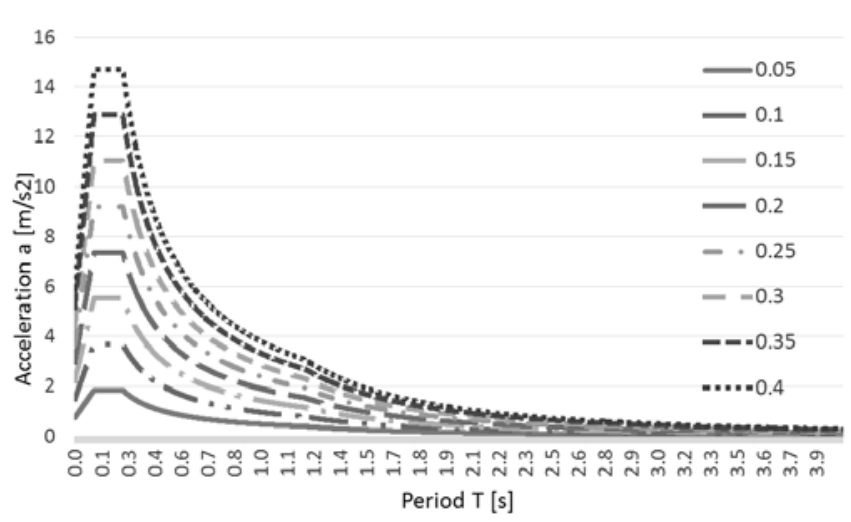

Figure 5. Elastic response spectra.

After the definition of the seismic response, the "Capacity Spectrum Method" (CSM) proposed by Shinozuka et al $(2000 \mathrm{a} / \mathrm{b})$ is implemented. The procedure considers the capacity curve and the response spectrum in terms of spectral acceleration and spectral displacement in the ADRS (AccelerationDisplacement Response Spectrum) plan.

The intersection between the ADSR spectrum and the capacity curve represents the "performance point".

Damage is defined as:

$$
I M=\frac{{ }^{d} D}{d_{C}}
$$

- $\mathrm{d}_{\mathrm{D}}$ is the displacement depending on the seismic demand;

- $\mathrm{d}_{\mathrm{C}}$ is the displacement related to the considered damage level.

The seismic demand is represented by a lognormal distribution. The medium demand is calculated with the following equation:

$$
S_{d}=I M^{B} \cdot e^{A}
$$

In particular, in the logarithmic plan the following regression line represents the medium demand:

$$
\ln \left(S_{d}\right)=A+B \cdot \ln (I M)
$$

A and B coefficients are obtained by the regression line, considering the standard deviation of the scatter gram related to the demand values; average deviations are referred to the regression line of each considered IM.
The following chart represents the four regression lines related to the four considered levels of damage; scatter plots represent the data for each evaluated PGA (Figure 6).

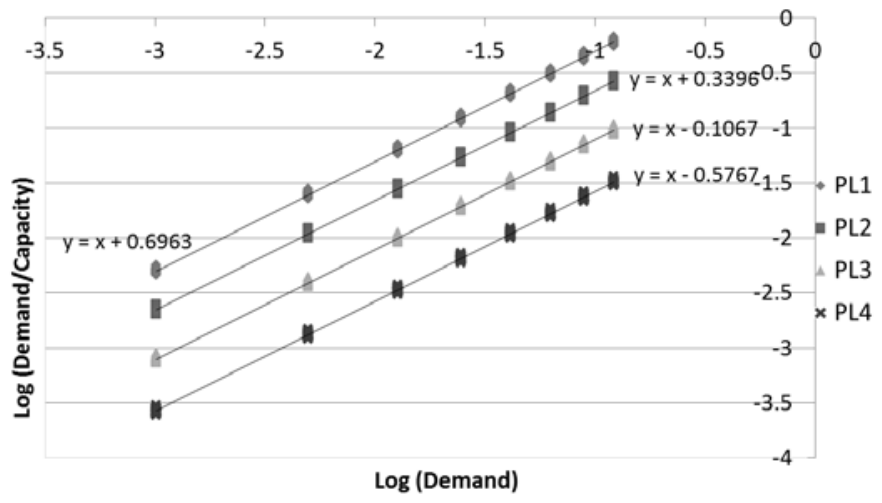

Figure 6. Regression lines defined for each considered level of damage

Once defined A and B coefficients and standard deviation, the fragility curve is represented by a lognormal distribution:

$P_{f, P L}(a)=P\left[D>d_{L P}|a|\right.$

and the exceedance probability of a certain level of damage is represented by the following formula:

$f_{D}=\frac{1}{\sqrt{2 \pi} \cdot \varepsilon d} \exp \left[-\frac{1}{2}\left(\frac{\ln d-\lambda}{\varepsilon}\right)^{2}\right]$

- $\lambda=\mathrm{A}+\mathrm{B} \cdot \ln (\mathrm{IM})$ is the medium value of the regression line related to an IM(PGA) value;

- $\varepsilon$ is the IM(PGA) scatter plot.

Fragility curves are defined by applying this procedure to each typology, reporting the probability of exceeding specific levels of damage considering predefined peak ground accelerations (Morbin et al., 2015).

For the simple overturning mechanisms, it is observed that:

- typologies with the highest exceedance probability of PL1 and PL2 are usually characterized by two stories or two stories with basement;

- for each level of damage, the probability of damage exceedance for four-story typologies are comparable regardless the presence of vaults on the ground floor. The destabilizing force of the vault thrust is indeed less determinant in the vulnerability of the typology when the stories number is increased;

- generally, the presence of basement and different roof typologies do not considerably influence the trend of fragility curves;

- stories number is the parameter mostly influence the curve behavior. 
As an example, fragility curve of typology 2 (characterized by 2 floors, masonry vertical structures, vaults on the ground floor and horizontal wooden diaphragms at the upper levels, contrasted thrust wooden roof) is herein presented (Figure 7).

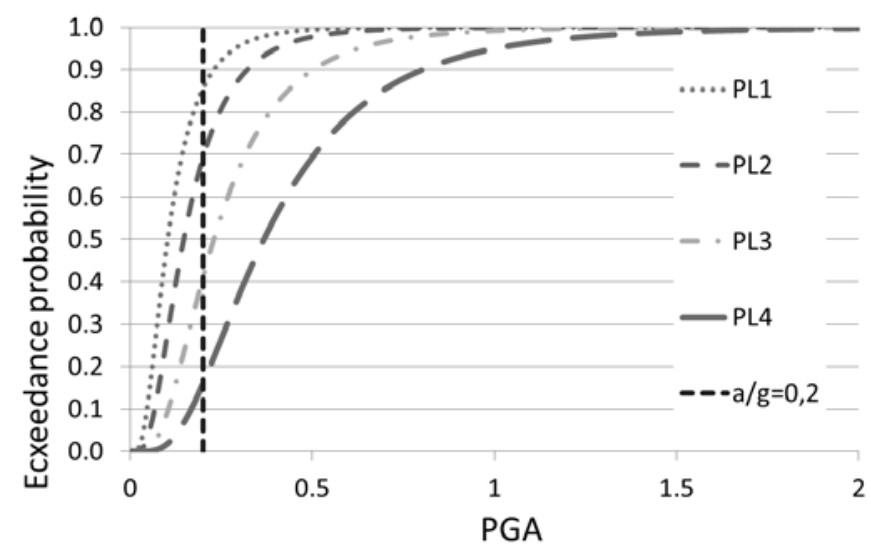

Figure 7. Fragility curve of typology 2, considering simple overturning mechanism.

The same procedure is applied considering the analysis of vertical bending local mechanism of collapse. Obtained curves have a different trend compared to simple overturning ones. Figure 8 represents fragility curves for typology 2 ; the value of $\mathrm{a} / \mathrm{g}=0.2 \mathrm{~g}$ is indicated. Contrarily to the overturning fragility curves, vertical bending ones reach the $100 \%$ of damage exceedance probability for PL4 for higher values of PGA. Fragility curves corresponding to more vulnerable typologies are usually referred to buildings characterized by two stories, in which the stabilizing weight of upper floors is lower compared to buildings having 3 or 4 stories.

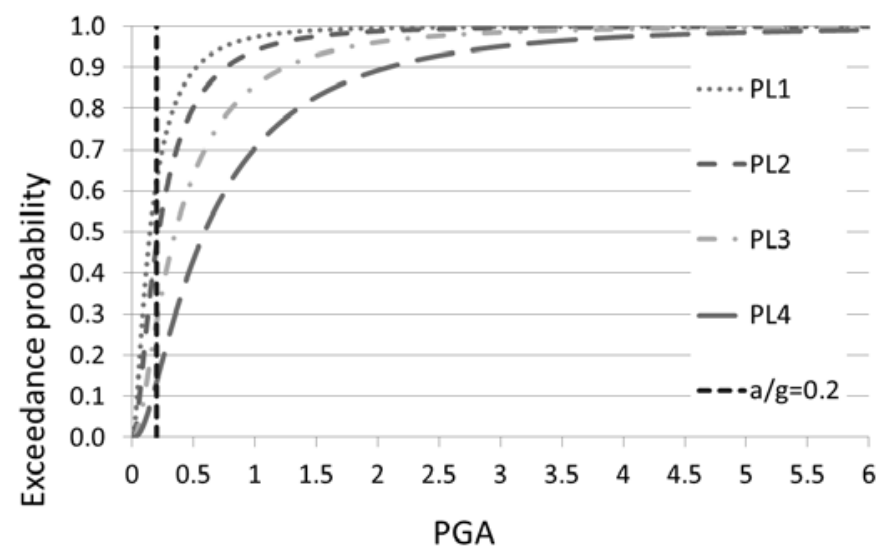

Figure 8 . Fragility curve of typology 2, considering vertical bending mechanism.

\section{CONCLUSIONS}

Fragility curves, because of their intuitiveness and simplicity of use, are expeditious instruments which can be adopted by technicians and professionals to estimate the propensity of a given building to suffer a certain level of damage due to the occurrence of earthquakes of given intensity. During on-site surveys, technicians can link each building to predefined typologies through outside buildings inspection. For each structure and considering each local mechanism of collapse, typological seismic vulnerability can be evaluated directly on site consulting the related fragility curve.

Similarly, judgments can be plotted through vulnerability maps, which can be used by local authorities to investigate the probability of occurrence of a certain level of damage considering a certain PGA level, listing more vulnerable buildings and defining possible intervention priorities.

Results obtained from the fragility curves of Timisoara historical center are graphically represented through vulnerability maps (Figure 9). Buildings vulnerability evaluation is confirmed by the actual state of buildings surveyed on site.

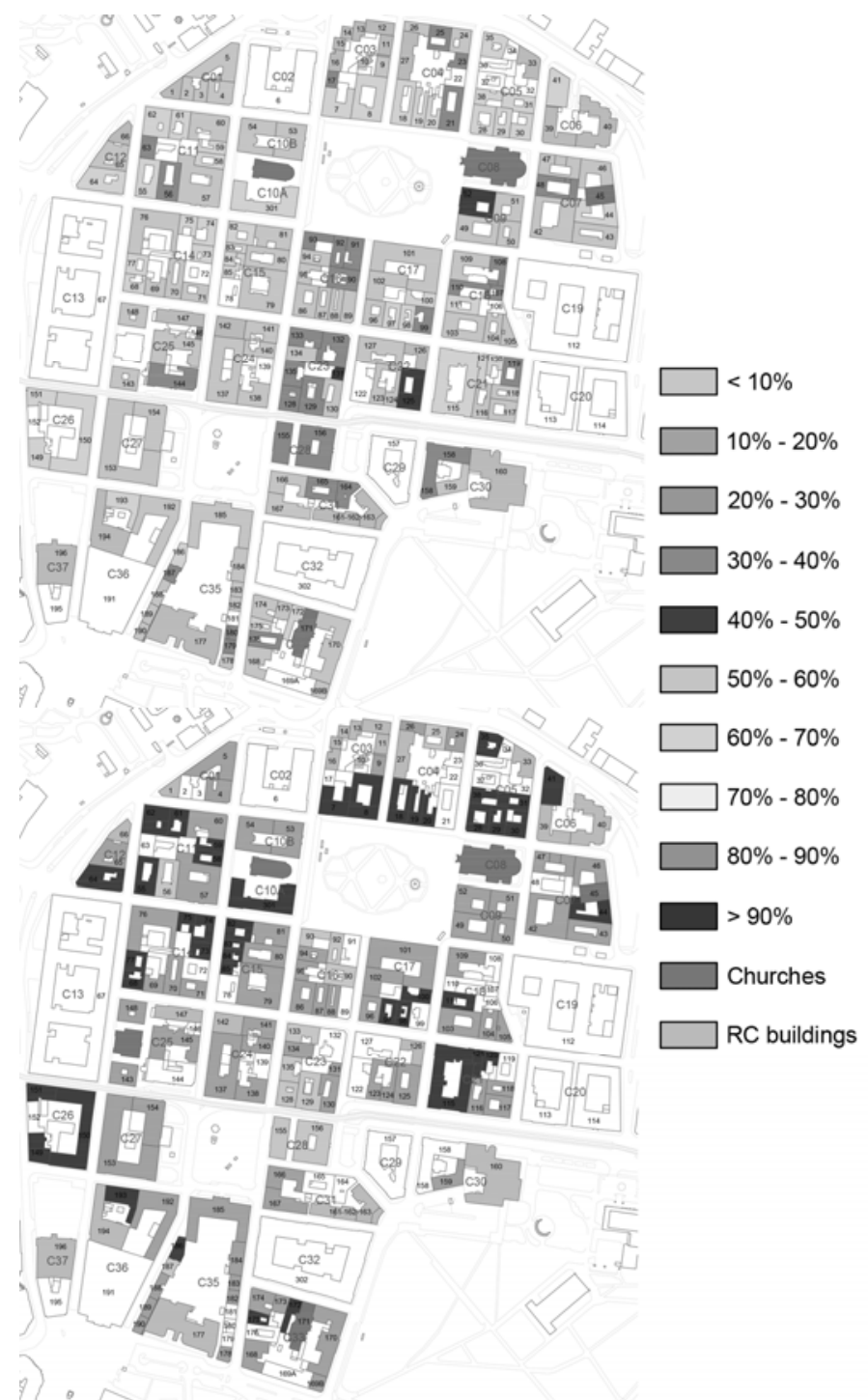

Figure 9. Examples of vulnerability maps for the historical center of Timisoara (RO), defining the probability of PL2 damage exceedance $(\mathrm{a} / \mathrm{g}=0.2)$ for both the mechanisms of simple overturning (upper figure) and vertical bending (lower figure) 


\section{ACKNOWLEDGEMENT}

This work is carried out in the framework of the collaboration between the Department of Civil, Architectural and Environmental Engineering of the University of Padova (Italy) and the Faculty of Architecture and Urban Planning of the Politehnica University of Timişoara (Romania). The authors wish to thank the working group of Prof. Mosoarca for technical and logistic support. A special thank goes to Archt. Bogdan Demetrescu and Archt. Alina Narita for their on-site work and data retrieval.

\section{REFERENCES}

Cialone, G., Cifani, G., Mannella, A., Petracca, A., Modena, C., Bettiol, G., Munari, M., da Porto, F. (2014). Reconstruction Plans of the Municipalities of the Barony of Carapelle in the province of L'Aquila (Italy). In Proceedings of the 9th International Masonry Conference, Guimarães, Portugal

da Porto, F., Munari, M., Prota, A.and Modena, C. (2012). Analysis and repair of clustered buildings: Case study of a block in the historic city centre of L'Aquila (Central Italy). Construction and building materials, 38:1221-1237

European Committee For Standardization (2010) EN 1998-1: Eurocode 8: Design of structures for earthquake resistance - Part 1:General rules, seismic actions and rules for buildings.

Lagomarsino, S., Cattari, S., (2014). PERPETUATE guidelines for seismic performance-based assessment of cultural heritage masonry structures. Bulletin of Earthquake Engineering, 13:13-47

Modena C., da Porto F., Valluzzi M.R., Munari M. (2013). Criteria and technologies for the structural repair and strengthening of architectural heritage. International Journal of $3 R ' s, 4: 606-621$

Modena, C. (2014). Una proposta operativa di approccio sostenibile alla valutazione e mitigazione del rischio sismico dei centri storici. In I quaderni della Soprintendenza per $i$ Beni architettonici paesaggistici per le provincie di Verona Rovigo Vicenza, vol. VI [In Italian]

Morbin, R., Zanini, M.A., Pellegrino C., Zhang, H., Modena, C. (2015). A probabilistic strategy for seismic assessment and FRP retrofitting of existing bridges. Bulletin of Earthquake Engineering, 13(1)

Mosoarca, M., Petrus, C., Stoian, V., Anastasiadis, A. (2014) Seismic risk of buildings with $\mathrm{RC}$ frames and masonry infills from Timisoara, Banat region, Romania. In Proceedings of the 9th International Masonry Conference, Guimarães, Portugal

Ministero delle Infrastrutture e dei Trasporti (2008) NTC2008 - Norme tecniche per le costruzioni. D.M. 14/01/2008 [In Italian]

Ministero delle Infrastrutture e dei Trasporti (2009) Circolare esplicativa 02/02/2009 n. 617. Istruzioni per l'applicazione delle «Nuove norme tecniche per le costruzioni». D.M. $14 / 02 / 2008$ [In Italian]

Narita, A. (2015) Seismic vulnerability of historic buildings from Timisoara. Case study: Saint George Square - MSc. Thesis [in Romanian]

National Institute for Earth Physics(INFP). (2013) Seismicity of Romania. Available online at: http://www.infp.ro/localseismicity/romanian-seismicity

Oros, E. (2012) Seismicitatea, seismotectonica şi hazardul seismic din zona Timişoara. Buletinul AGIR nr. 3 (7-9/2012)
Shinozuka, M., Feng, M. Q., Kim, H. K. and Kim, S. H., (2000a), Nonlinear static procedure for fragility curve development. Journal of Engineering Mechanics-ASCE, 126(12):1287-1295.

Shinozuka, M., Feng, M. Q., Lee, J. and Naganuma T., (2000b), Statistical analysis of fragility curves. Journal of Engineering Mechanics-ASCE, 126(12):1224-1231.

Taffarel, S., Marson, C., Bettiol, G., da Porto, F .and Modena C. 2014, Seismic vulnerability assessment of Israeli historical centres. In Proceedings of SAHC2014 - 9th International Conference on Structural Analysis of Historical Constructions, F. Peña \& M. Chávez (eds.), Mexico City, Mexico. 